\section{Use of injectable local anaesthesia for IUD/IUS fitting}

I am writing in support, without reservation, of the rejection by Dr Devonald of the views expressed by Dr Hutt concerning the use of injectable local anaesthesia (LA) for intrauterine device/intrauterine system (IUD/IUS) fitting. I felt the need to state my own feelings on this subject in the light of what may be considered my appreciable experience of IUD/IUS practice.

I retired in 1999 from clinic work, after at least 25 years in regular family planning practice. I worked during that time in a number of clinics, some of which I initiated and one of which I was able to develop into a sexual and reproductive health clinic, that is, for more than just family planning. However, the main point is that in that time, starting in the early 1970s, I fitted IUDs of all types into women aged from 15 to 50 years, amounting to of the order of 2000 devices.

Although experienced in cervical and paracervical LA, at no time did I find the use of LA for IUD insertion either necessary or desirable, despite my concern for the physical comfort of my patients. I actively promoted the IUD/IUS for what I considered good physiological and psychological reasons. However, also because the use of the method was frequently dependent on adequate information and reassurance and confidence in the practitioner, lack of which were common causes for the otherwise relatively poor uptake. When my particular clinic was closed by the Trust responsible as, as far as I could tell, a cost-cutting measure, I estimate that perhaps $75 \%$ of those attending were IUD users.

The last thing you want is medicalisation of the process by procedures such as unnecessary LA. While not wishing to impugn in any way the competence of anyone involved in this correspondence, experience forced me to conclude that of the women referred to me, or self-referred following insertion failures elsewhere, at least part of the problem was inadequate understanding on the part of the practitioner of uterine anatomy and anatomical relationships. The consequences for difficult and uncomfortable insertion of an IUD are perhaps obvious. I was left feeling that anatomical update and examination technique may have been sometimes neglected aspects of teaching.

In the past 20 years, insertion of modern devices became so easy and free of discomfort for the woman that I would not have imagined the circumstances necessitating the use of LA if the subject had not been raised in this way.

Kenneth Jones, FFPH, FFSRH

Retired Director of Public Health/Family Planning Clinic Doctor, Lincoln, UK;

jones549@btinternet.com

Competing interests None.

J Fam Plann Reprod Health Care 2011;37:253 doi:10.1136/jprhc-2011-100184

\section{REFERENCES}

1 Devonald B. Injectable local anaesthetic for IUD/IUS fittings [Letter]. J Fam Plan Reprod Health Care 2011:37:119.

2 Hutt S. Injectable local anaesthetic for IUD/IUS fittings [Letter]. J Fam Plan Reprod Health Care 2011:37:59. 